\title{
A Combination of Downward Lighting and Supplemental Upward Lighting Improves Plant Growth in a Closed Plant Factory with Artificial Lighting
}

\author{
Jyotsna Joshi ${ }^{1}$ \\ Center for Environment, Health and Field Sciences, Chiba University, \\ Kashiwa, Japan; and Mahidol University, Bangkok, Thailand
}

Geng Zhang ${ }^{1}$

Center for Environment, Health and Field Sciences, Chiba University, Kashiwa, Japan; and College of Life Science and Technology, Yangtze Normal University, Chongqing, China

\author{
Shanqi Shen \\ Center for Environment, Health and Field Sciences, Chiba University, \\ Kashiwa, Japan
}

Kanyaratt Supaibulwatana

Mahidol University, Bangkok, Thailand

Chihiro K.A. Watanabe

Department of Biological Sciences, Graduate School of Science, The University of Tokyo, Tokyo, Japan

\section{Wataru Yamori ${ }^{2}$ \\ Center for Environment, Health and Field Sciences, Chiba University, Kashiwa, Japan; and Department of Biological Sciences, Graduate School of Science, The University of Tokyo, Tokyo, Japan}

Additional index words. LED, lettuce, yield, plant factory, photosynthesis, supplemental lighting

Abstract. "Plant factory with artificial lighting" (PFAL) refers to a plant production facility that can achieve mass production of vegetables year round in a controlled environment. However, the high-density planting pattern in PFALs causes low light conditions in the lower canopy, leading to leaf senescence in the outer leaves and thus to reductions in plant yields. In the present study, the effect of supplemental upward lighting underneath the plants on photosynthetic characteristics and plant yield was examined in lettuce, in comparison with supplemental downward lighting from above the plants at the same light intensity. Supplemental upward lighting increased the curvature factor of the photosynthetic response to light from above the plants. Moreover, supplemental upward lighting significantly enhanced the lettuce yield by retarding the senescence of the outer leaves. Here, we propose a novel cultivation system with a combination of downward lighting and supplemental upward lighting that can effectively increase plant growth and yield in PFALs.

"Plant factories with artificial lighting" are a new type of facility that can produce high yield with high quality all year round in

\footnotetext{
Received for publication 2 Feb. 2017. Accepted for publication 28 Mar. 2017

This study was supported by the Strategic Priority Research Promotion Program, Phytochemical Plant Molecular Sciences, Chiba University. The authors declare no conflict of interest. J.J., S.S., and W.Y. conceived and designed the experiments. J.J., G.Z., and S.S. performed the experiments. J.J., G.Z., and W.Y. prepared the manuscript, and J.J., G.Z., S.S., K.S., C.W., and W.Y. contributed extensively to its finalization.

${ }^{1}$ These authors contributed equally to this work. ${ }^{2}$ Corresponding author. E-mail: wataru.yamori@ bs.s.u-tokyo.ac.jp.
}

a controlled environment (e.g., lighting, temperature, $\mathrm{CO}_{2}$ concentration, and nutrients) (Kozai, 2013a; Yamori et al., 2014). PFALs have many advantages over conventional farming and greenhouses (Merrill et al., 2016). For example, a PFAL creates a closed space that is independent from environmental, seasonal, and geographical limitations. Moreover, resources are more efficiently used, including land, water, nutrients, and labor. In addition, high-quality and safe plants can be produced without pesticides under this strict closed environment (Merrill et al., 2016). PFALs have already been used for commercial production of leafy vegetables and herbs in many countries, including Asia, Europe, and North America (Kozai, 2013b; Kozai et al., 2015).
In a PFAL, a large number of leafy vegetables (e.g., lettuce and spinach) are grown at a high planting density to achieve high yields. However, this dense cultivation causes a strong shading effect on leaves beneath the plant canopy, leading to a dramatic decrease in photosynthesis in the lower canopy (Brouwer et al., 2012; Tewolde et al., 2016). Light is the most important environmental factor affecting photosynthesis and thus yield because plant growth and yield depend on photosynthesis (Yamori, 2016; Yamori and Shikanai, 2016; Yamori et al., 2016). The light intensity in the outer leaves is usually below the photosynthetic light compensation point [i.e., the photosynthetic photon flux density (PPFD) at which photosynthetic rate is zero], meaning that the rate of photosynthesis falls below the rate of respiration (Zhang et al., 2015). The outer leaves senesce fast and appear yellow (McCabe et al., 2001), resulting in large reductions in plant yield at the time of shipment. A recent study indicated that supplemental upward lighting from underneath the plants could delay the senescence of outer leaves (Zhang et al., 2015). However, it is unclear whether supplemental upward lighting from underneath the plants could improve the yield in comparison with supplemental downward lighting from above the plants at the same light intensity because their experiments were examined under different total light intensity. Because the free energy from sunlight is completely excluded from PFALs, additional electrical energy is required to provide growth light for plant cultivation, accounting for as much as $80 \%$ of the total electricity consumption (Kozai, 2007; Kozai, 2013a). This causes a great increase in the electricity bill and reduces income substantially. To use the light source efficiently, it is important to investigate the effects of supplemental upward lighting from underneath on plant growth in comparison with supplemental downward lighting from above at the same light intensity and propose the lighting environment most suitable to the plant cultivation in PFALs.

Currently, only leafy vegetables and some herbs (shade-type plant species) are suitable for commercial production in PFALs because they can grow well even under relatively low light intensities $\left(100-200 \mu \mathrm{mol} \cdot \mathrm{m}^{-2} \cdot \mathrm{s}^{-1}\right.$ PPFD; Kozai et al., 2015). It is difficult to cultivate many vegetables (especially, suntype plant species), including tomato, paprika, and cucumber, under such low light intensities in a PFAL because they require higher light intensities for growth. The lightresponse curve of the photosynthetic rate differs between sun- and shade-type plant species. Both the light compensation point and light saturation point of the photosynthetic rate are low in shade species (Givnish, 1988; Lichtenthaler et al., 1981), allowing them to efficiently grow under low light intensities. In contrast, sun species demand more light to drive photosynthesis because they have a higher light compensation point and light saturation point than shade species. 
The shape of the photosynthetic light-response curve varies with the direction of irradiation (Moss, 1964; Ögren and Evans, 1993; Terashima, 1986). In general, the photosynthetic lightresponse curve obtained by irradiating the adaxial side of a dorsiventral leaf shows a higher curvature factor value than that obtained by irradiating the abaxial side of the same leaf (Terashima and Takenaka, 1986). The difference in the curvature factor of the adaxial and abaxial curves became smaller after $7 \mathrm{~d}$ of the leaf being inverted and was slightly reversed by $11 \mathrm{~d}$ (Terashima, 1986). However, how the photosynthetic light-response curve can be altered by combining downward lighting and supplemental upward lighting has not been examined. If supplemental upward lighting could alter the shape of the photosynthetic light-response curve and thus the light saturation point of photosynthesis, it could make cultivation of sun-type species possible under relatively low downward lighting with supplemental upward lighting. In the present study, to develop a new cultivation system fitting for plant productions under PFALs, we studied the effects of supplemental upward or downward lighting at the same light intensity on photosynthetic characteristics and plant growth in lettuce and measured the lightresponse curve of photosynthetic rate to analyze whether the supplemental upward lighting could effectively alter the curvature factor of the photosynthetic response to light from above the plants.

\section{Materials and Methods}

Plant materials and growth conditions. Romaine lettuce seeds (Lactuca sativa L. var. Romana; Takii Seed Co., Kyoto, Japan) were sown in urethane cubes $(\mathrm{W} 2.3 \mathrm{~cm} \times \mathrm{D} 2.3 \mathrm{~cm} \times$ $\mathrm{H} 2.7 \mathrm{~cm}$ ), and the seedlings were grown in an environmentally controlled growth chamber at $20 / 17{ }^{\circ} \mathrm{C}$ (photoperiod/dark period) under a PPFD of $350 \pm 10 \mu \mathrm{mol} \cdot \mathrm{m}^{-2} \cdot \mathrm{s}^{-1}$ from cool white fluorescent lamps with a 12-h photoperiod. At 4 weeks after sowing, uniformly sized seedlings at the three-leaf stage were transplanted to a cultivation room under a $25 / 20{ }^{\circ} \mathrm{C}$ photoperiod/dark period temperature (Wang et al., 2016; Zhang et al., 2015) and 14-h photoperiod. The plants were grown in a deep-flow hydroponic system, supplied with Enshi formula nutrient solution (EC: $2.0 \pm 0.2$ and $\mathrm{pH}: 7.0 \pm 0.5$; Asao et al., 2013; Zhang et al., 2015). The cultivation system could provide light both from above (i.e., downward lighting) and underneath (i.e., upward lighting) the plants (Fig. 1). The light treatments were divided into three groups: 1) control: plants were grown solely under downward lighting at a PPFD of 200 $\mu \mathrm{mol} \cdot \mathrm{m}^{-2} \cdot \mathrm{s}^{-1}$; 2) supplemental downward lighting: plants were grown under downward lighting at a PPFD of $200 \mu \mathrm{mol} \cdot \mathrm{m}^{-2} \cdot \mathrm{s}^{-1}$ with supplemental downward lighting at a PPFD of 30 or $60 \mu \mathrm{mol} \cdot \mathrm{m}^{-2} \cdot \mathrm{s}^{-1}$; and 3) supplemental upward lighting: plants were grown under downward lighting at a PPFD of
$200 \mu \mathrm{mol} \cdot \mathrm{m}^{-2} \cdot \mathrm{s}^{-1}$ with supplemental upward lighting at a PPFD of 30 or $60 \mu \mathrm{mol} \cdot \mathrm{m}^{-2} \cdot \mathrm{s}^{-1}$ at the height of the outer leaves $(3.0 \mathrm{~cm})$. The planting density is 33 plants $/ \mathrm{m}^{2}$, and the interval between plant rows and between light-emitting diode (LED) tubes is $9 \mathrm{~cm}$. The LEDs for supplemental upward lighting have installed on the aluminum plates to release the heat efficiently and so there was no significant effect on the leaf temperature by the supplemental upward lighting (InfRed, Fujitsu, Japan). The downward lighting for plant cultivation was provided by cool white fluorescent lamps (Supplemental Fig. 1A), and supplemental downward or upward lighting was supplied with white LEDs (Supplemental Fig. 1B). Each treatment was replicated five times.

Gas exchange and chlorophyll fluorescence. The plants were divided into six layers of leaves counted from the lowest leaf; the first to third layers were considered outer leaves, and the fourth to sixth layers were considered inner leaves. Photosynthetic rate and stomatal conductance $\left(g_{\mathrm{S}}\right)$ in the newest fully expanded leaves (i.e., inner leaves; in the sixth layer) and the outer leaves (in the third layer) in plants grown for 3 weeks after transplanting were measured under each growth-light condition with a portable photosynthesis system (LI6400; LI-COR Inc., Lincoln, NE) as described previously (Yamori et al., 2009, 2010; Zhang et al., 2015). For the measurement of photosynthetic light-response curves, the control plants which were grown solely under downward lighting have been examined. Maximum potential photochemical efficiency (i.e., the ratio of variable to maximum fluorescence, $F_{\mathrm{v}} / F_{\mathrm{m}}$ ) was measured using an Imaging-PAM fluorometer (Walz, Effeltrich, Germany) as described in Zhang et al. (2015).

Chlorophyll and nitrogen content. Immediately after the photosynthesis and chlorophyll fluorescence measurements, leaf discs $(0.85 \mathrm{~cm}$ in diameter) were taken from the six layers of leaves (the same leaves used to measure $\left.F_{\mathrm{v}} / F_{\mathrm{m}}\right)$ of each treatment. Total chlorophyll content was quantified according to Porra et al. (1989). Leaf nitrogen content was measured with a Vario EL III elemental analyzer (Elementar, Hanau, Germany) according to Yamori et al. (2005).

Plant growth and ascorbic acid content. The plants were harvested at 3 weeks after transplanting (i.e., after 3 weeks under different light treatments), and plant growth was analyzed. The ascorbic acid content of plants in each treatment was determined using a RQFlex plus reflectometer (Merck, Darmstadt, Germany) according to Zhang et al. (2015).

Electricity consumption measurements. The electrical energy consumption of the white LEDs was measured using a multimeter and a clamp ammeter (Hioki 3169-01; Hioki E.E. Corporation, Nagano, Japan) and was used to evaluate the economics of each light treatment (Zhang et al., 2015).

Statistical analysis. Data are presented as means \pm SD. Analysis of variance with a post hoc Tukey's test was performed in the SPSS statistical software (SPSS, Chicago, IL). Differences were considered significant at $P<0.05$.

\section{1) Control}

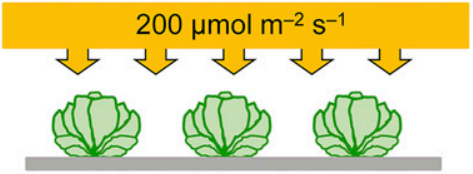

2) Supplemental downward lighting

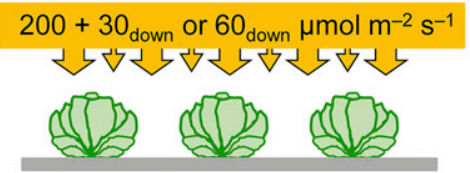

3) Supplemental upward lighting
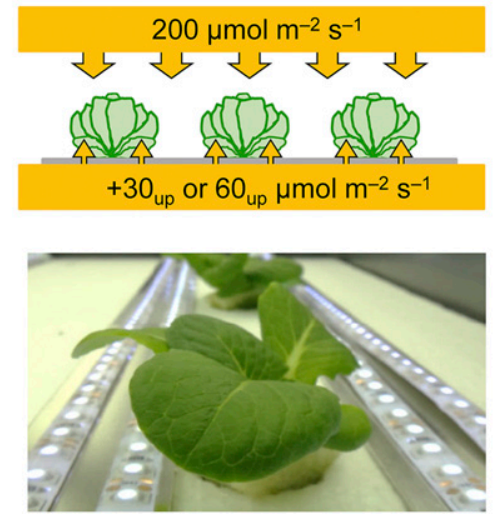

Fig. 1. Schematic diagram of the experimental design of the present study. In cultivation beds, a lighting system that could provide light both from above (i.e., downward lighting) and underneath (i.e., upward lighting) the plants was installed. The supplemental light treatments were divided into three groups: (1) control: plants were grown solely under downward lighting at a photosynthetic photon flux density (PPFD) of 200 $\mu \mathrm{mol} \cdot \mathrm{m}^{-2} \cdot \mathrm{s}^{-1}$; (2) supplemental downward lighting: plants were grown under downward lighting at a PPFD of $200 \mu \mathrm{mol} \cdot \mathrm{m}^{-2} \cdot \mathrm{s}^{-1}$ with supplemental downward lighting at a PPFD of 30 or 60 $\mu \mathrm{mol} \cdot \mathrm{m}^{-2} \cdot \mathrm{s}^{-1}$; and (3) supplemental upward lighting: plants were grown under downward lighting at a PPFD of $200 \mu \mathrm{mol} \cdot \mathrm{m}^{-2} \cdot \mathrm{s}^{-1}$ with supplemental upward lighting at a PPFD of 30 or 60 $\mu \mathrm{mol} \cdot \mathrm{m}^{-2} \cdot \mathrm{s}^{-1}$ at the height of the outer leaves. The picture of supplemental upward lighting underneath the plants has been shown.

\section{Results}

Leaf characteristics. In plants grown without any supplemental lighting, the total chlorophyll content (Fig. 2A) and $F_{\mathrm{v}} / F_{\mathrm{m}}$ (Fig. 2B) remained high in the inner leaves (fourth to sixth layer), but dramatically decreased from the third to first layer in the outer leaves. Similar results were obtained when plants were grown with supplemental downward lighting.

Supplemental upward lighting resulted in higher total chlorophyll content and $F_{\mathrm{v}} / F_{\mathrm{m}}$ values in the outer leaves of plants compared with plants grown without any supplemental upward lighting (Fig. 2A and B). In addition, the treatment with supplemental upward lighting at a PPFD of $60 \mu \mathrm{mol} \cdot \mathrm{m}^{-2} \cdot \mathrm{s}^{-1}$ resulted in a higher total chlorophyll content 


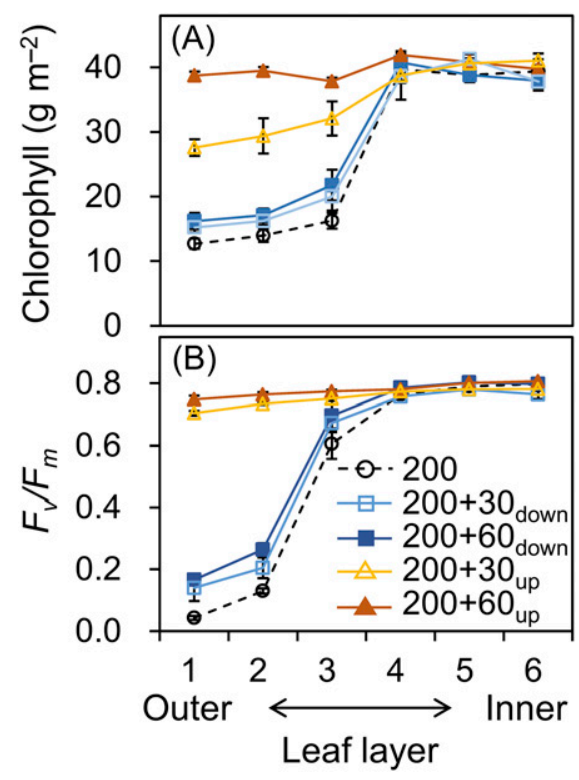

Fig. 2. (A) Total chlorophyll content and (B) maximum quantum yield $\left(F_{v} / F_{m}\right)$ in lettuce leaves from the six leaf layers in plants grown under different light treatments. Data represent means \pm SD $(n=5)$. "200" denotes plants grown solely under downward lighting at a 200 $\mu \mathrm{mol} \cdot \mathrm{m}^{-2} \cdot \mathrm{s}^{-1}$ photosynthetic photon flux density (PPFD); " $200+30$ down" or " $200+60$ down" denotes plants grown under downward lighting at a $200 \mu \mathrm{mol} \cdot \mathrm{m}^{-2} \cdot \mathrm{s}^{-1}$ PPFD with supplemental downward lighting at a 30 or $60 \mu \mathrm{mol} \cdot \mathrm{m}^{-2} \cdot \mathrm{s}^{-1}$ PPFD; and " $200+30$ up" or " $200+60$ up" denotes plants grown under downward lighting at a $200 \mu \mathrm{mol} \cdot \mathrm{m}^{-2} \cdot \mathrm{s}^{-1} \mathrm{PPFD}$ with supplemental upward lighting at a 30 or $60 \mu \mathrm{mol} \cdot \mathrm{m}^{-2} \cdot \mathrm{s}^{-1} \mathrm{PPFD}$.

in the outer leaves than the treatment with supplemental upward lighting at a PPFD of $30 \mu \mathrm{mol} \cdot \mathrm{m}^{-2} \cdot \mathrm{s}^{-1}$ (Fig. 2A and B).

Photosynthesis and nitrogen content. In the newest fully expanded leaves (inner leaves; sixth layer), the photosynthetic rate and $g_{S}$ were highest in the treatment with supplemental downward lighting at a PPFD of $60 \mu \mathrm{mol} \cdot \mathrm{m}^{-2} \cdot \mathrm{s}^{-1}$, followed by $30 \mu \mathrm{mol} \cdot \mathrm{m}^{-2} \cdot \mathrm{s}^{-1}$ PPFD, whereas plants in the control and supplemental upward lighting treatments at a PPFD of 60 or $30 \mu \mathrm{mol} \cdot \mathrm{m}^{-2} \cdot \mathrm{s}^{-1}$ showed similar values (Fig. 3A and B). The nitrogen content in the newest fully expanded leaves (inner leaves; sixth layer) showed a similar trend to the photosynthetic rate in the inner leaves (Fig. 4A).

In the outer leaves (third layer), all the plants without supplemental upward lighting (even those with supplemental downward lighting) showed negative photosynthetic rates (Fig. 3C). However, supplemental upward lighting increased the $g_{\mathrm{S}}$ and photosynthetic rate (Fig. 3C and D). The treatment with supplemental upward lighting at a $60 \mu \mathrm{mol} \cdot \mathrm{m}^{-2} \cdot \mathrm{s}^{-1}$ PPFD increased the photosynthetic rate in the outer leaves to a greater extent than that at a $30 \mu \mathrm{mol} \cdot \mathrm{m}^{-2} \cdot \mathrm{s}^{-1}$ PPFD (Fig. 3C). Moreover, supplemental upward lighting increased the leaf nitrogen content in the outer leaves (third layer; Fig. 4B), which showed the same pattern to the photosynthetic rate in the outer leaves (third layer; Fig. 3C).

Inner leaves
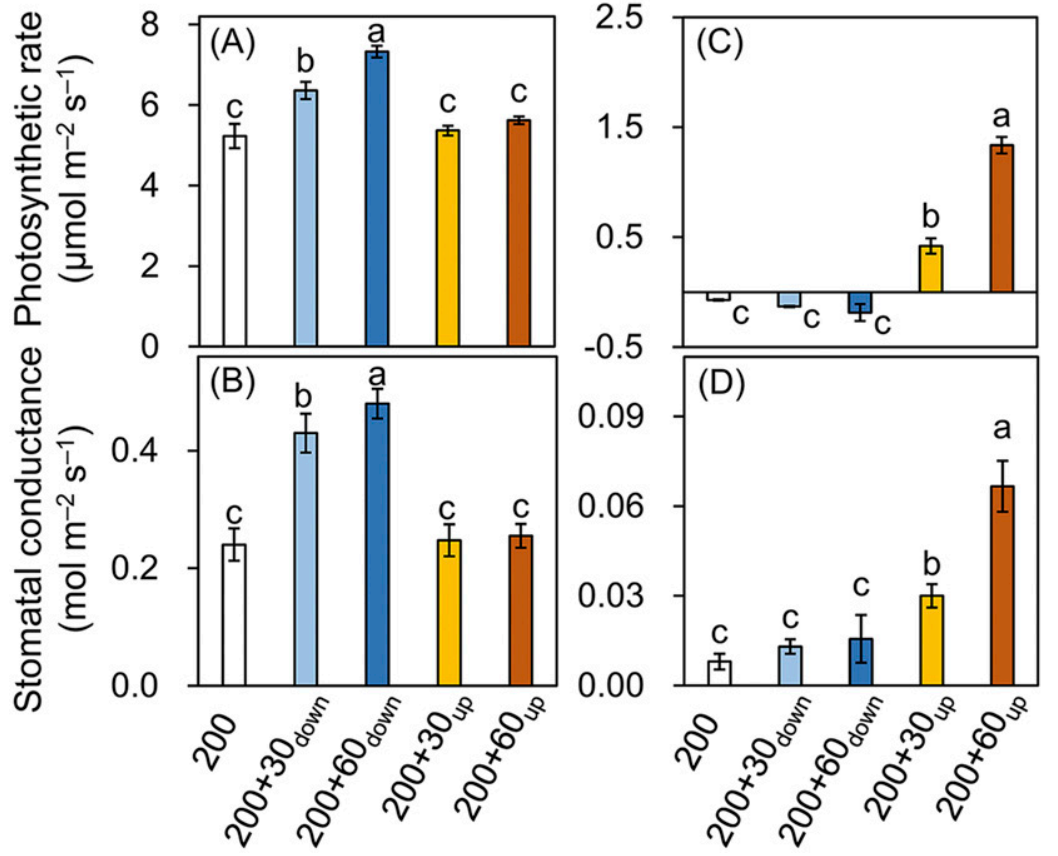

Fig. 3. Photosynthetic rate and stomatal conductance $\left(g_{\mathrm{S}}\right)$ of plants grown under different light treatments. Data represent means \pm SD $(n=5)$. (A) Photosynthetic rate and (B) $g_{\mathrm{S}}$ of the newest fully expanded leaves (i.e., inner leaves; in the sixth layer), and (C) photosynthetic rate and (D) $g_{\mathrm{S}}$ of the outer leaves (in the third layer) were measured under each growth-light condition. Bars labeled with different letters indicate that the data are significantly different among the five light treatments (Tukey's HSD test, $P<$ 0.05). Abbreviations are the same as those in Fig. 2.

Inner leaves

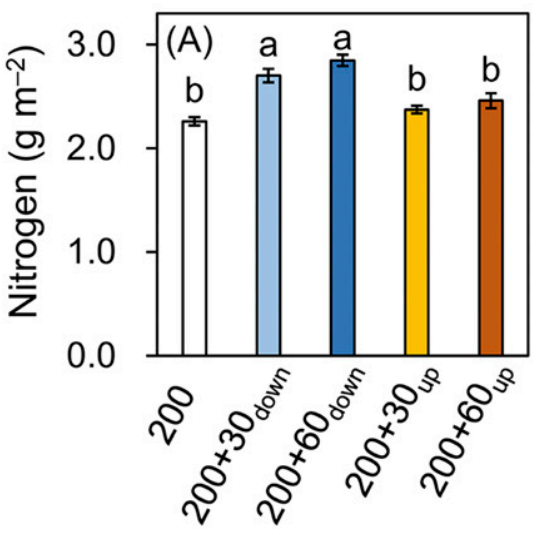

Outer leaves

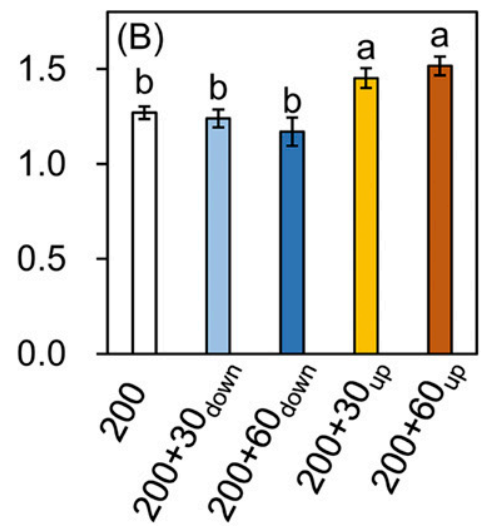

Fig. 4. Nitrogen content in the (A) inner and (B) outer leaves of lettuce plants grown under different light treatments. Data represent means $\pm \mathrm{SD}(n=5)$. Bars labeled with different letters indicate that the data are significantly different among the five light treatments (Tukey's HSD test, $P<0.05$ ). Abbreviations are the same as those in Fig. 2.

Photosynthetic light-response curves under different light intensities of supplemental upward lighting. The photosynthetic lightresponse curves in the newly fully expanded leaves (inner leaves; sixth layer) of control plants were measured to assess the leaf photosynthetic capacity under different levels of supplemental upward lighting $(0,30,60$, or $90 \mu \mathrm{mol} \cdot \mathrm{m}^{-2} \cdot \mathrm{s}^{-1}$ PPFD; Fig. 5). The maximum photosynthetic rate at the light saturation point was similar in each photosynthetic light-response curve (Fig. 5). However, supplemental upward lighting increased the photosynthetic rate at lower PPFDs compared with the control, whereas the light compensation point was reduced by supplemental upward lighting (Fig. 5). The curvature factor, which indicates the bending rate of the photosynthetic light-response curve, increased with increasing supplemental upward light intensity (Fig. 5; Table 1).

Plant growth. Plant growth and yield were significantly enhanced by both supplemental downward lighting and supplemental upward lighting, but supplemental upward lighting was more effective, and the most remarkable increase was found in the treatment with supplemental upward lighting 
at a $60 \mu \mathrm{mol} \cdot \mathrm{m}^{-2} \cdot \mathrm{s}^{-1}$ PPFD (Fig. 6A; Supplemental Table 1). Supplemental downward lighting tended to have a higher waste compared with the control (Fig. 6B). Conversely, supplemental upward lighting significantly reduced the waste (Fig. 6B). As a result, the marketable leaf fresh weight (i.e., the remaining leaves after removal of the outer senesced leaves) was much higher in the treatment with supplemental upward lighting than in the treatment with supplemental downward lighting (Fig. 6A).

Ascorbic acid content of the romaine lettuce. The ascorbic acid content in outer leaves and total leaves was unaffected by supplemental downward lighting, but was significantly increased by supplemental upward lighting (Fig. 7). The highest ascorbic acid content was obtained in the treatment with supplemental upward lighting at a $60 \mu \mathrm{mol} \cdot \mathrm{m}^{-2} \cdot \mathrm{s}^{-1}$ PPFD (Fig. 7).

\section{Discussion}

A combination of downward and upward lighting could be an economically feasible and more cost-effective alternative to traditional solely downward lighting. Our results clearly showed that supplemental upward lighting significantly retarded the senescence of outer leaves in plants, resulting in a higher $F_{v} / F_{m}$ (Fig. 2B) and higher photosynthetic rate (Fig. 3) compared with plants grown solely under downward lighting. Because nitrogen, an essential constituent of chlorophyll and photosynthetic enzymes including Rubisco, significantly influences the rate of photosynthesis (Yamori et al., 2011), supplemental upward lighting would improve photosynthesis by the maintenance of higher nitrogen content in the outer leaves (Fig. 4B). Moreover, supplemental upward lighting significantly increased ascorbic acid content in outer leaves and thus total leaves, compared with plants grown under solely downward lighting (Fig. 7). The previous research indicated that ascorbic acid content increased with increases in growth-light intensity in lettuce (Kosma et al., 2013), but the present study clearly showed that the total amount of ascorbic acid in plants was severely affected by the direction of irradiation to plants. Furthermore, supplemental upward lighting gave a significant reduction in the waste by retarding the senescence of the outer leaves (Fig. 6B), leading to a significant increase in marketable leaf fresh weight (Fig. 6A). Considering only the cost of electricity, the increased cost of supplemental downward lighting (23.3 or $44.8 \mathrm{JPY} /$ plant) resulted in a $12.7 \%$ or $27.1 \%$ increase in marketable leaf fresh weight (a profit equivalent to 12.9 or $33.1 \mathrm{JPY} /$ plant) compared with control plants grown solely under downward lighting at a $200 \mu \mathrm{mol} \cdot \mathrm{m}^{-2} \cdot \mathrm{s}^{-1}$ PPFD (Supplemental Table 2). However, supplemental upward lighting more efficiently increased the marketable leaf fresh weight $(35.4 \%$ or $56.3 \%)$ by reducing the waste, leading to an 80.0 or $117.1 \mathrm{JPY} /$ plant increase in profit (Supplemental Table 2). Because the electricity requirement for lighting is the largest expense to growers, the effective use of electricity through a more efficient lighting system can contribute to the profitability of a PFAL (Kozai et al., 2015). Our results clearly show that supplemental upward lighting is more effective for plant cultivation in PFALs than supplemental downward lighting. LED lighting is a revolutionary product that has allowed growers to put lights in places that were difficult or impossible to reach in the past. The unique characteristics of LEDs, such as their small size, long lifetime, reduced heat, and precise wavelength specificity (Merrill et al., 2016), make them ideal as feasible and efficient light sources for supplemental upward lighting. Future developments in lighting systems for PFALs should consider supplemental upward lighting to achieve a high yield and good quality, as well as good economic benefits.

In the present study, it took 7 weeks until harvesting lettuce after sowing seeds, because plants were grown under ambient $\mathrm{CO}_{2}$ concentration of $400 \mathrm{ppm}$. Optimization of growth $\mathrm{CO}_{2}$ concentration, hydroponic system, and air conditioners with air fans would be able to promote plant growth and thus shorten the cultivation period (Kozai, 2013a; Merrill et al., 2016). In addition, the present data indicated that downward lighting at a PPFD of $200 \mu \mathrm{mol} \cdot \mathrm{m}^{-2} \cdot \mathrm{s}^{-1}$ with supplemental upward lighting at a PPFD of $60 \mu \mathrm{mol} \cdot \mathrm{m}^{-2} \cdot \mathrm{s}^{-1}$ increased lettuce yield compared with supplemental upward lighting at a PPFD of $30 \mu \mathrm{mol} \cdot \mathrm{m}^{-2} \cdot \mathrm{s}^{-1}$ (Fig. 6). The upper limits of light intensity for supplemental upward lighting might be greater than that of $60 \mu \mathrm{mol} \cdot \mathrm{m}^{-2} \cdot \mathrm{s}^{-1}$. Therefore, further research is required to optimize the light intensity of supplemental upward lighting and also the combination with the light intensity of downward lighting for maximizing lettuce yield in PFALs.

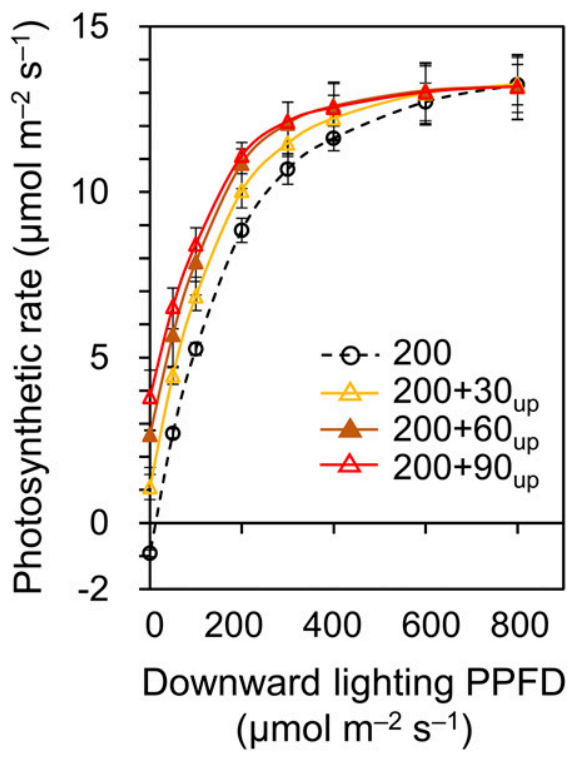

Fig. 5. Photosynthetic light-response curves of the newest fully expanded leaves (i.e., inner leaves; in the sixth layer) in control plants with different levels of supplemental upward lighting $\left[0,30,60\right.$, or $90 \mu \mathrm{mol} \cdot \mathrm{m}^{-2} \cdot \mathrm{s}^{-1}$ photosynthetic photon flux density (PPFD)]. Data represent means \pm SD $(n=5)$. " $200 "$ denotes the photosynthetic light-response curve measured in leaves without supplemental upward lighting. " $200+30$ up," "200 + 60 up," and " $200+90$ up" denote the photosynthetic lightresponse curve measured in leaves with supplemental upward lighting at 30, 60, and $90 \mu \mathrm{mol} \cdot \mathrm{m}^{-2} \cdot \mathrm{s}^{-1} \mathrm{PPFD}$, respectively.

Table 1. Parameters for the light-response curve of photosynthetic rate, derived from the nonrectangular hyperbolic response.

\begin{tabular}{lcc}
\hline & Maximum rate of photosynthesis $($ Amax $)\left(\mu \mathrm{mol} \cdot \mathrm{m}^{-2} \cdot \mathrm{s}^{-1}\right)$ & Curvature factor $(\theta)$ \\
\hline 0 & $15.0 \pm 0.8 \mathrm{a}$ & $0.705 \pm 0.035 \mathrm{~b}$ \\
$30_{\text {up }}$ & $14.8 \pm 0.7 \mathrm{a}$ & $0.768 \pm 0.032 \mathrm{ab}$ \\
$60_{\text {up }}$ & $14.6 \pm 0.7 \mathrm{a}$ & $0.822 \pm 0.041 \mathrm{a}$ \\
$90_{\text {up }}$ & $14.3 \pm 0.7 \mathrm{a}$ & $0.862 \pm 0.038 \mathrm{a}$ \\
\hline
\end{tabular}

" 0 " denotes the photosynthetic light-response curve measured in leaves without supplemental upward lighting. " $30_{\text {up}}$," " $60_{\text {up }}$," and " $90_{\text {up }}$ " denote the photosynthetic light-response curve measured in leaves with supplemental upward lighting at 30,60 , and $90 \mu \mathrm{mol} \cdot \mathrm{m}^{-2} \cdot \mathrm{s}^{-1}$ photosynthetic photon flux density, respectively. Curves are fitted to the data shown in Fig. 5.

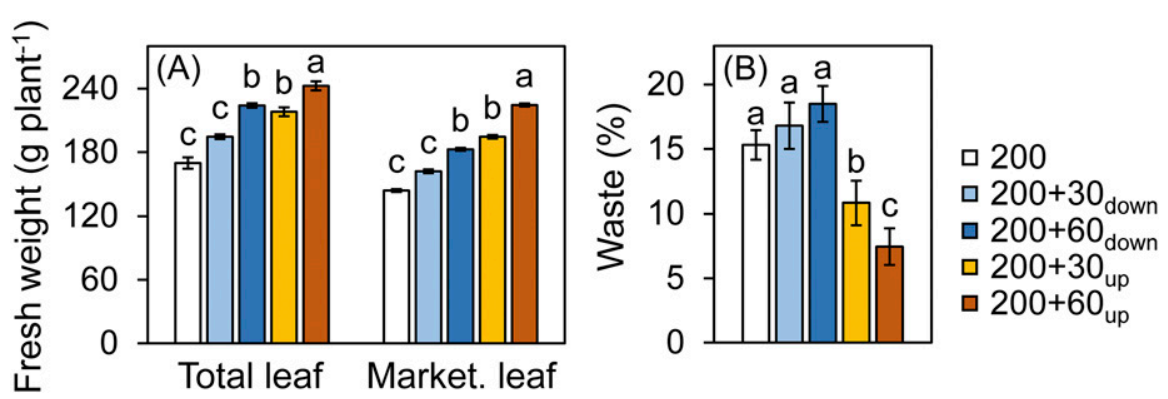

Fig. 6. (A) Total leaf fresh weights, (A) marketable leaf fresh weights, and (B) wastes of the outer senesced leaves of plants grown under different light treatments at 3 weeks after transplanting. Data represent means $\pm \mathrm{SD}(n=5)$. Bars labeled with different letters indicate that the data are significantly different among the five light treatments (Tukey's HSD test, $P<0.05$ ). Abbreviations are the same as those in Fig. 2. 


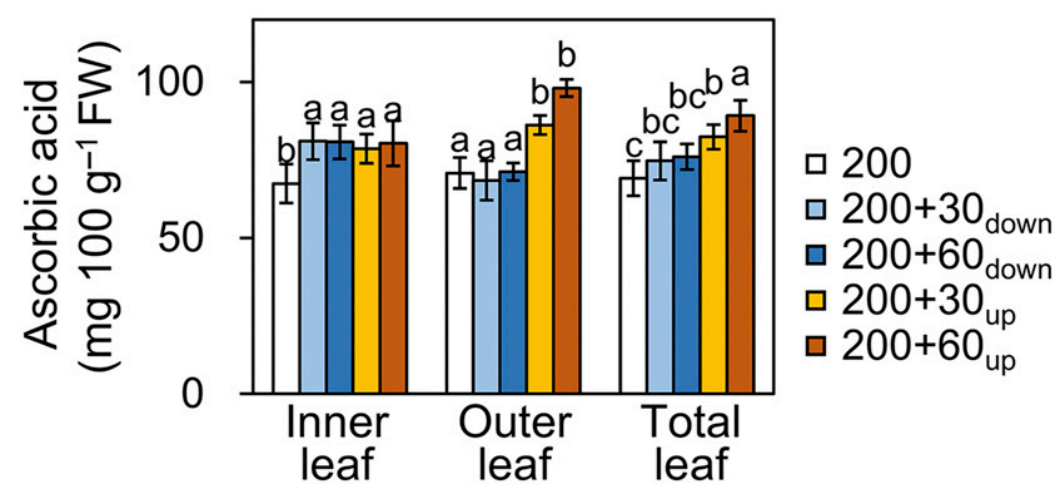

Fig. 7. Ascorbic acid content in the outer leaves, inner leaves, and total leaves of lettuce plants grown under different light treatments. Data represent means $\pm \mathrm{SD}(n=5)$. Bars labeled with different letters indicate that the data are significantly different among the five light treatments (Tukey's HSD test, $P<0.05$ ). Abbreviations are the same as those in Fig. 2.

Supplemental upward lighting makes it possible to grow plants with a high lightsaturated rate of photosynthesis. At present, the number of plant species suitable for commercial production in PFALs is limited because the light intensity used is relatively low (e.g., below a $\left.200 \mu \mathrm{mol} \cdot \mathrm{m}^{-2} \cdot \mathrm{s}^{-1} \mathrm{PPFD}\right)$. Accordingly, only leafy vegetables and some herbs can be produced under such low light conditions (Kozai, 2013b). Low light intensities are insufficient for sun-type plant species, which have a higher light saturation point (Givnish, 1988; Lichtenthaler et al., 1981) and thus need more light for growth. However, our results clearly show that supplemental upward lighting altered the shape of the photosynthetic light-response curve by improving the curvature factor and had a significant effect on the treatment with supplemental upward lighting at the higher light intensity (Figs. 5 and 6; Table 1). This indicates that supplemental upward lighting of the abaxial side of a leaf can lower the light saturation point of photosynthesis even under relatively low growth light from above. Our results suggest that a new efficient lighting system with supplemental upward lighting could make it possible to realize PFAL cultivation even for sun-type plant species.

\section{Conclusions}

The aim of our research is to establish a new cultivation system in PFALs. The newly proposed system using a combination of downward lighting and supplemental upward lighting retarded the senescence of the outer leaves and improved the photosynthesis, leading to significant increase in lettuce yield. Moreover, supplemental upward lighting increased the curvature factor of the photosynthetic light-response curve, providing the feasibility to cultivate sun-type species under relatively low downward lighting with supplemental upward lighting. This novel cultivation system with supplemental upward lighting could be a widespread application in PFALs because it can maximize plant yield through a suitable light source layout and make PFALs applicable to a wide range of plant species.

\section{Literature Cited}

Asao, T., M. Asaduzzaman, M.F. Mondal, M. Tokura, F. Adachi, M. Ueno, M. Kawaguchid, S. Yanof, and T. Bang. 2013. Impact of reduced potassium nitrate concentrations in nutrient solution on the growth, yield and fruit quality of melon in hydroponics. Sci. Hort. 164:221-231.

Brouwer, B., A. Ziolkowska, M. Bagard, O. Keech, and P. Gardeström. 2012. The impact of light intensity on shade-induced leaf senescence. Plant Cell Environ. 35:1084-1098.

Givnish, T.J. 1988. Adaptation to sun and shade: A whole-plant perspective. Austral. J. Plant Physiol. 15:63-92.

Kosma, C., V. Triantafyllidis, A. Papasavvas, G. Salahas, and A. Patakas. 2013. Yield and nutritional quality of greenhouse lettuce as affected by shading and cultivation season. Emir. J. Food Agr. 25:974-979.

Kozai, T. 2007. Propagation, grafting and transplant production in closed systems with artificial lighting for commercialization in Japan. Propag. Ornam. Plants 7:145-149.

Kozai, T. 2013a. Resource use efficiency of closed plant production system with artificial light: Concept, estimation and application to plant factory. Proc. Jpn. Acad., Ser. B, Phys. Biol. Sci. 89:447-461.

Kozai, T. 2013b. Plant factory in Japan-current situation and perspectives. Chron. Hort. 53:8-11.

Kozai, T., G. Niu, and M. Takagaki. 2015. Plant factory an indoor vertical farming system for efficient quality food production, 1st ed. Massachusetts: Academic press, Cambridge, CA.

Lichtenthaler, H.K., C. Buschmann, M. Döll, H.J. Fietz, T. Bach, U. Kozel, D. Meier, and U. Rahmsdorf. 1981. Photosynthetic activity, chloroplast ultrastructure, and leaf characteristics of high-light and low-light plants and of sun and shade leaves. Photosynth. Res. 2:115-141.

McCabe, M.S., L.C. Garratt, F. Schepers, W.J. Jordi, G.M. Stoopen, E. Davelaar, J.H.A. van Rhijn, J. Brian Power, and M.R. Davey. 2001. Effects of PSAG12-IPT gene expression on development and senescence in transgenic lettuce. Plant Physiol. 127:505-516.

Merrill, B.F., N. Lu, T. Yamaguchi, M. Takagaki, T. Maruo, T. Kozai, et al. 2016. "The next revolution of agriculture: A review of innovations in Plant factories", p. 779-796. In: M. Pessarakli (ed.). Handbook of photosynthesis. 3rd ed, CRC Press, Boca Raton, FL.

Moss, D.N. 1964. Optimum lighting of leaves. Crop Sci. 4:131-136.
Ögren, E. and J.R. Evans. 1993. Photosynthetic light-response curves.I. The influence of $\mathrm{CO}_{2}$ partial pressure and leaf inversion. Planta 189:182-190.

Porra, R.J., W.A. Thompson, and P.E. Kriedemann. 1989. Determination of accurate extinction coefficients and simultaneous equations for assaying chlorophylls a and $\mathrm{b}$ extracted with four different solvents: Verification of the concentration of chlorophyll standards by atomic absorption spectroscopy. Biochimicaet Biophysica Acta (BBA)- Bioenergetics 975:384-394

Terashima, I. 1986. Dorsiventrality in photosynthetic light response curves of a leaf. J. Expt. Bot. 37:399-405.

Terashima, I. and A. Takenaka. 1986. “Organization of photosynthetic system of dorsiventral leaves as adapted to the irradiation from the adaxial side", p. 219-230. In: R. Marcelle, H. Clijster, and M. Van Pouke (eds.). Biological control of photosynthesis, Springer-Verlag, Berlin, Germany.

Tewolde, F.T., N. Lu, K. Shiina, T. Maruo, M. Takagaki, T. Kozai, and W. Yamori. 2016. Nighttime supplemental LED inter-lighting improves growth and yield of single-Truss tomatoes by enhancing photosynthesis in both winter and summer. Front. Plant Sci. 7:448.

Wang, J., Y. Tong, Q. Yang, and M. Xin. 2016. Performance of introducing outdoor cold air for cooling a plant production system with artificial light. Front. Plant Sci. 7:270.

Yamori, W. 2016. Photosynthetic response to fluctuating environments and photoprotective strategies under abiotic stress. J. Plant Res. 129:379-395.

Yamori, W. and T. Shikanai. 2016. Physiological functions of cyclic electron transport around photosystem I in sustaining photosynthesis and plant growth. Annu. Rev. Plant Biol. 67:81-106.

Yamori, W., E. Kondo, D. Sugiura, I. Terashima, Y. Suzuki, and A. Makino. 2016. Enhanced leaf photosynthesis as a target to increase grain yield: Insights from transgenic rice lines with variable Rieske FeS protein content in the cytochrome $b_{6}$ If complex. Plant Cell Environ. 39:80-87.

Yamori, W., K. Noguchi, K. Hikosaka, and I. Terashima. 2009. Cold-tolerant crop species have greater temperature homeostasis of leaf respiration and photosynthesis than cold-sensitive species. Plant Cell Physiol. 50:203-215.

Yamori, W., K. Noguchi, K. Hikosaka, and I. Terashima. 2010. Phenotypic plasticity in photosynthetic temperature acclimation among crop species with different cold tolerances. Plant Physiol. 152:388-399.

Yamori, W., K. Noguchi, and I. Terashima. 2005. Temperature acclimation of photosynthesis in spinach leaves: Analyses of photosynthetic components and temperature dependencies of photosynthetic partial reactions. Plant Cell Environ. 28:536-547.

Yamori, W., T. Nagai, and A. Makino. 2011. The rate-limiting step for $\mathrm{CO}_{2}$ assimilation at different temperatures is influenced by the leaf nitrogen content in several C3 crop species. Plant Cell Environ. 34:764-777.

Yamori, W., G. Zhang, M. Takagaki, and T. Maruo. 2014. Feasibility study ofrice growth in plant factories. Rice Res. Open Access 2:119, doi: $10.4172 /$ jrr. 1000119 .

Zhang, G., S. Shen, M. Takagaki, T. Kozai, and W. Yamori. 2015. Supplemental upward lighting from underneath to obtain higher marketable lettuce (Lactuca sativa) leaf fresh weight by retarding senescence of outer leaves. Front. Plant Sci. 6:1110. 
(A) Cool white fluorescent lamps

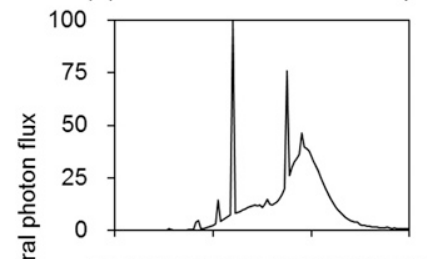

(B) Supplemental downward or upward lighting

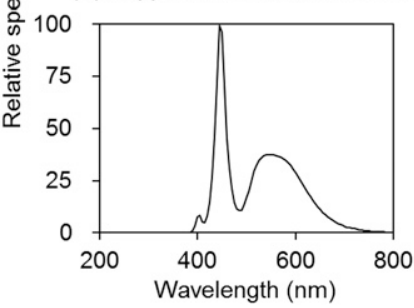

Supplemental Fig. 1. The relative spectral photon flux of (A) cool white fluorescent lamps and (B) supplemental downward or upward lighting (white LEDs). The wavelengths of light sources were recorded at $240-800 \mathrm{~nm}$ with a spectrometer (SR9910-v7; Irradiant Ltd., Tranent, UK).

Supplemental Table 1. Leaf number and total leaf area of lettuce under different light treatments at harvest time.

Light treatments Leaf number Total leaf area $\left(\mathrm{m}^{2}\right)$ \begin{tabular}{llll}
\hline 200 & $35.2 \pm 1.5 \mathrm{c}$ & $0.361 \pm 0.288 \mathrm{bc}$
\end{tabular}

$200+30_{\text {down }} \quad 40.2 \pm 3.0$ bc $0.353 \pm 0.130 \mathrm{c}$

$200+60_{\text {down }} \quad 45.0 \pm 1.0$ ab $0.464 \pm 0.153 \mathrm{a}$

$200+30_{\text {up }} \quad 45.6 \pm 1.0 \mathrm{ab} \quad 0.431 \pm 0.970 \mathrm{ab}$

$200+60_{\text {up }} \quad 47.8 \pm 1.6 \mathrm{a} \quad 0.469 \pm 0.133 \mathrm{a}$

Data represent means $\pm \mathrm{SD}(n=5)$. Values within columns followed by different letters were significantly different (Tukey's HSD test, $P<0.05$ ).

Supplemental Table 2. Evaluation of the feasibility of different light treatments in real production. Based on local surveys, the retail price of lettuce was $200 \mathrm{JPY} / 100 \mathrm{~g}$ and the electricity bill was $17.49 \mathrm{JPY} / \mathrm{KW} \mathrm{h}$. (A) Electricity bill of supplemental upward lighting per plant was calculated as: electricity consumption of white LEDs $\times 14 / 1000 / 8 \times 17.49$, where 14 was the photoperiod and 8 was the number of plants illuminated by supplemental white LEDs from underneath the plants; (B) retail price per plant was calculated as: marketable leaf fresh weight $/ 100 \times 200$; net retail price per plant was calculated as B minus A.

\begin{tabular}{|c|c|c|c|c|c|c|}
\hline $\begin{array}{l}\text { PPFD } \\
\left(\mu \mathrm{mol} \cdot \mathrm{m}^{-2} \cdot \mathrm{s}^{-1}\right)\end{array}$ & $\begin{array}{l}\text { Marketable leaf } \\
\text { fresh weight }(\mathrm{g})\end{array}$ & $\begin{array}{c}\text { Electric consumption of } \\
\text { supplemental lighting } \\
\text { (KWh plant/d) }\end{array}$ & $\begin{array}{l}\text { Electricity consumption } \\
\text { during the treatments }\end{array}$ & $\begin{array}{l}\text { (A) Electricity bill of } \\
\text { supplemental lighting } \\
\text { (JPY plant) }\end{array}$ & $\begin{array}{l}\text { (B) Retail price } \\
\text { (JPY plant) }\end{array}$ & $\begin{array}{c}(\mathrm{B}-\mathrm{A}) \text { Net retail price } \\
\text { (JPY plant) }\end{array}$ \\
\hline 200 & $143.7 \pm 25.2 \mathrm{c}$ & $0.000 \pm 0.000 \mathrm{c}$ & $0.00 \pm 0.00 \mathrm{~d}$ & $0.0 \pm 0.0 \mathrm{~d}$ & $287.3 \pm 50.5 \mathrm{~d}$ & $287.3 \pm 50.5 \mathrm{c}$ \\
\hline $200+30_{\text {down }}$ & $161.8 \pm 11.7 \mathrm{c}$ & $0.051 \pm 0.002 \mathrm{~b}$ & $1.33 \pm 0.04 \mathrm{~b}$ & $23.3 \pm 0.8 \mathrm{~b}$ & $323.6 \pm 23.6 \mathrm{c}$ & $300.2 \pm 23.7 \mathrm{c}$ \\
\hline $200+60_{\text {down }}$ & $182.6 \pm 3.8 \mathrm{~b}$ & $0.098 \pm 0.001 \mathrm{a}$ & $2.56 \pm 0.03 \mathrm{a}$ & $44.8 \pm 0.5 \mathrm{a}$ & $365.2 \pm 7.6 \mathrm{~b}$ & $320.4 \pm 7.2 \mathrm{c}$ \\
\hline $200+30_{\text {up }}$ & $194.5 \pm 8.4 b$ & $0.048 \pm 0.002 \mathrm{~b}$ & $1.24 \pm 0.05 \mathrm{~b}$ & $21.6 \pm 0.9 \mathrm{~b}$ & $388.9 \pm 16.7 b$ & $367.3 \pm 16.6 \mathrm{~b}$ \\
\hline $200+60$ up & $224.5 \pm 8.7 \mathrm{a}$ & $0.098 \pm 0.002 \mathrm{a}$ & $2.55 \pm 0.04 \mathrm{a}$ & $44.6 \pm 0.8 \mathrm{a}$ & $449.0 \pm 17.4 \mathrm{a}$ & $404.4 \pm 17.6 \mathrm{a}$ \\
\hline
\end{tabular}

Data represent means \pm SD $(n=5)$. Values within columns followed by different letters were significantly different (Tukey's HSD test, $P<0.05$ ). 